\title{
Characteristics of teaching and students' emotions in the classroom: Investigating differences across domains
}

\author{
Thomas Goetz $^{\mathrm{a}, \mathrm{b}, *}$, Oliver Lüdtke ${ }^{\mathrm{c}}$, Ulrike E. Nett ${ }^{\mathrm{d}}$, Melanie M. Keller ${ }^{\mathrm{a}, \mathrm{b}}$, Anastasiya A. Lipnevich ${ }^{\mathrm{e}}$ \\ a Department of Empirical Educational Research, University of Konstanz, Konstanz, Germany \\ ${ }^{\mathrm{b}}$ Thurgau University of Teacher Education, Kreuzlingen, Switzerland \\ ${ }^{\mathrm{c}}$ Institute of Psychology, Humboldt-University Berlin, Germany \\ ${ }^{\mathrm{d}}$ Department of Psychology, University of Ulm, Ulm, Germany \\ ${ }^{\mathrm{e}}$ Queens College and the Graduate Center, The City University of New York, New York, USA
}

\section{A R T I C L E I N F O}

Keywords:

Teaching

Instruction

Quality

Classroom

Emotions

Domains

\begin{abstract}
A B S T R A C T
This study investigated the relations between eight characteristics of teaching and students' academic emotions (enjoyment, pride, anxiety, anger, helplessness and boredom) across four academic domains (mathematics, physics, German, and English). 121 students (50\% female; 8th and 11th graders) were asked about their perceptions of teaching characteristics and their academic emotions using the experi ence sampling method (real time approach) for a period of 10 school days, with intraindividual analyses conducted using a multilevel approach. Multilevel exploratory factor analysis revealed that the eight teaching characteristics (understandability, illustration, enthusiasm, fostering attention, lack of clarity, difficulty, pace, level of expectation) represented two factors, labeled supportive presentation style (e.g., comprising understandability) and excessive lesson demands (e.g., comprising difficulty). In line with our hypothesis, we found clear relations on the intraindividual level between the two factors of teaching characteristics and students' academic emotions in the classroom (e.g., supportive presentation style pos itively related to students' enjoyment and negatively related to their boredom). Further, and supporting the universality assumption of teaching characteristics/academic emotions relations, the strength of rela tions between the two factors of teaching characteristics and academic emotions was very similar across the four academic domains. Implications for future research and educational practice are discussed.
\end{abstract}

\section{Introduction}

"A wise teacher makes learning a joy" (proverb)

There is extensive empirical evidence showing that students experience a wide range of discrete positive and negative emotions in the classroom, such as enjoyment, pride, anxiety, anger, help lessness, and boredom (e.g., Goetz, Frenzel, Pekrun, Hall, \& Lüdtke, 2007). For numerous reasons, these emotions are highly relevant: In the classroom they guide students' learning behavior (e.g., enjoyment fosters self regulated learning; Pekrun, 2006), have an impact on their achievement outcomes (e.g., negative relations be tween anxiety and achievement; Zeidner, 1998), and represent an aspect of students' subjective well being (Pekrun, Goetz, Titz, \& Perry, 2002). Further, cumulatively experienced discrete emotions in the classroom can be assumed to result in relatively stable emo tional beliefs related to specific domains (e.g., "Mathematics makes me anxious") that strongly impact domain and career choices (Wig

\footnotetext{
* Corresponding author. Address: University of Konstanz, Universitaetsstr. 10, D-78457 Konstanz, Germany. Fax: +49 (0)7531/88 4350.

E-mail address: thomas.goetz@uni-konstanz.de (T. Goetz).
}

field, Battle, Keller, \& Eccles, 2002) as well as lifelong learning (Goetz, Zirngibl, Pekrun, \& Hall, 2003).

Different theoretical approaches and scattered empirical find ings present initial evidence that characteristics of teaching may represent one of the key antecedents of students' academic emotions in the classroom (e.g., Frenzel, Goetz, Lüdtke, Pekrun, \& Sutton, 2009). The way the teacher delivers the material, the level of clarity and organization, the enthusiasm that he or she exudes all these characteristics may have a direct impact on students' aca demic emotional experiences by means of "emotional contagion" (e.g., humor of the teacher enhancing students' academic enjoy ment) or via students' cognitive appraisals (e.g., subjective control over the situation). Other antecedents of classroom emotions in clude genetic disposition (e.g., Pekrun, 2006), subjective beliefs re lated to domains (e.g., "Mathematics is not relevant to my life"; cf., Haag \& Goetz, 2012), emotions of peers related to the academic do main in general (e.g., "School is boring"), and related to specific do mains in particular (e.g., "Mathematics is boring"; e.g., Robinson, 1975). So, although teaching characteristics are not the only source of student emotions in the classroom, they are certainly a highly important one (Frenzel et al., 2009). 
A clear shortcoming of previous studies in the field that exam ined relations between teaching characteristics and discrete aca demic emotions is that they tended to exclusively focus on one academic domain. Hence, the question of whether teaching charac teristics/emotion relations differ with respect to specific academic domains, such as mathematics or English, remains unanswered. This is important both from a theoretical perspective (e.g., whether it is sufficient to do studies in one domain and generalize conclu sions to multiple domains) as well as from a practical perspective (e.g., whether classroom interventions that target student emo tions can be assumed to work in different academic domains).

The aim of this study was to go beyond previous approaches by investigating both teaching characteristics and emotions with re spect to specific subject domains and analyzing whether relations between teaching factors (i.e., groups of teaching characteristics) and emotions differ across academic domains. In order to investigate teaching characteristics and emotions in the classroom, the experi ence sampling method was employed (Hektner, Schmidt, \& Csikszentmihalyi, 2007). To our knowledge, this is the first study investigating teaching characteristics in tandem with academic emotions in the classroom in real time by using personal digital assistants (PDAs; see Supplementary 1) given to students. The strength of the intraindividual real time approach employed in this study is that it allows for examining patterns within students (intra individual, idiographic approach; see Lamiell, 1998). In sum, the cur rent study aims at contributing to our understanding of the intraindividual relationship between teaching characteristics and real time students' emotions across different academic domains.

\section{Teaching and students' emotions}

Theoretical assumptions and scattered empirical research sug gest that characteristics of teaching are related to classroom emo tions. The first approach that may explain this link is appraisal based emotion theories (e.g., Pekrun, 2006; Scherer, Schorr, \& John stone, 2001; Smith \& Lazarus, 1993). According to these theories, numerous cognitive appraisals that include perceptions of personal control, the value of the situation, and expectations of others are strongly related to specific emotions experienced in that situation. Undoubtedly, teachers' instructional behaviors have a strong im pact on those appraisals. For example, a very high speed of instruc tion in the classroom may lead to perceptions of a loss of control in students and, in turn, to feelings of helplessness and anxiety. An other example is that the way of giving feedback on achievement outcomes influences what students think about teachers' achieve ment expectations. So, exceedingly high levels of expectations may reduce appraisals of control and enhance extrinsic value appraisals at the same time, thus lowering student enjoyment and increasing anxiety, anger, and boredom (due to being overchallenged). Conse quently, it is safe to assume that teaching characteristics may have an impact on students' emotions in class.

In line with these theoretical considerations, empirical findings within the field of appraisal based emotions reveal significant rela tions between teaching and habitual emotions in the classroom. For instance, achievement pressure (assumingly enhancing extrin sic value and reducing subjective control) was found to be posi tively correlated with anxiety, anger, and negatively correlated with enjoyment and pride. High level of clarity and structure (assumingly enhancing subjective control) was shown to positively relate to enjoyment and negatively to anger, anxiety, boredom, and hopelessness (e.g., Frenzel, Pekrun, \& Goetz, 2007b; Goetz, 2004; Goetz, Frenzel, Pekrun, \& Hall, 2006; Goetz, Pekrun, Hall, \& Haag, 2006).

Another approach that informs our understanding of the rela tionship between teaching characteristics and emotions involves teacher enthusiasm (also called teacher expressiveness or teacher immediacy; see Babab, 2007, for review). This construct has not al ways been labeled as a characteristic of teaching but it can clearly be seen as such (e.g., Brophy \& Good, 1986). In contrast to teacher enjoyment, which is an internal experience of teachers, the con ceptualization of enthusiasm focuses on teacher behaviors (e.g., gestures, varied intonation, eye contact, movement while lectur ing, and the use of humor and lively examples; Collins, 1978; Gage \& Berliner, 1998; Murray, 1983; Rosenshine, 1970). These teacher behaviors can be assumed to impact students' emotions (e.g., enhancing enjoyment, reducing boredom) in a very direct way by a so called "emotional contagion" (e.g., humor and teachers' own fascination leading to student enjoyment; Hatfield, Cacioppo, \& Rapson, 1994; Mottet \& Beebe, 2002). Frenzel et al. (2009), for example, showed that high teacher enthusiasm positively im pacted students' enjoyment in class, and Goetz et al. (2006) dem onstrated that teacher enthusiasm is positively correlated with enjoyment and pride, and negatively correlated with anger and boredom in class.

Finally, there are approaches that investigate relations between characteristics of teaching and affective variables in students with out directly focusing on discrete emotions. Research has shown significant relations between teaching and students' interest (e.g., Bergin, 1999; Mouratidis, Vansteenkiste, Sideridis, \& Lens, 2011), students' intrinsic motivation (e.g., Black \& Deci, 2000), and positive classroom climate (see Meyer \& Turner, 2006). Thus, this evidence also supports our proposition that characteristics of teaching and students' affect are closely intertwined.

It is important to note that there may be a reciprocal relationship between characteristics of teaching and students' emotions in the classroom, with the former serving as both the antecedent and the consequence of the latter. That is, not only can teaching elicit specific affect from students but students' emotions may have an influence on teaching, either directly or as mediated by cognitions. For exam ple, high levels of enjoyment expressed by students may result in a more enthusiastic teaching style due to emotional contagion (Hat field et al., 1994; Mottet \& Beebe, 2002) or due to the impact of stu dents' enjoyment on their teachers' cognitions (e.g., teachers' self efficacy, which in turn can foster enthusiastic teaching).

In addition to the impact of students' emotions on teachers' behavior, students' academic emotions may also influence judg ments about the teaching quality. For example, students who feel helpless in a learning situation may be more likely to make self serving external attributions about the teacher's lack of clarity as compared to their counterparts who experience lower levels of helplessness (for related assumptions in the field of self concept/ emotion relations see Marsh \& Ayotte, 2003).

In sum, different theoretical approaches and scattered empirical findings support the assumption that characteristics of teaching are related to students' emotions. Within the aforementioned ap proaches (see appraisal based emotion theories), a rather compre hensive theoretical framework that explicitly focuses on these relations is Pekrun's (2006) control value theory. According to this theory, classroom learning environment is an important anteced ent of students' discrete emotions with facets of this environment being (1) cognitive quality and task demands characterizing instruction, (2) value induction, (3) autonomy support, (4) struc ture of goals and expectations, and (5) feedback on and conse quences of achievement. Further, these facets are presumed to have an impact on students' emotions via their control and value appraisals. Thus, specific facets are assumed to influence students' perceptions of control and value, which, in turn, have an impact on students' discrete emotions.

From the perspective of the control value theory, high teaching quality is expected to elicit a positive emotional pattern in stu dents via their control and value appraisals thus enhancing 
students' learning and achievement outcomes. Traditionally, char acteristics that represent good teaching quality have been investi gated within the process product approach to teaching quality (see for example, Brophy \& Good, 1986). In it, different teacher behav iors (process) are investigated in their relation to student outcomes, such as achievement (product). The current study attempted to bring together the control value theory and the process product approach to teaching quality, and examined eight teaching charac teristics derived from both of these approaches. As such, we focused on teaching characterized by clarity, understandability, diffi culty and pace (representing cognitive quality and task demands according to Pekrun's model), an enthusiastic and illustrative teaching style (representing value induction), the expectations as outlined by the teacher (representing goal structures and expectations), as well as the way of teaching fostering students' attention (i.e. classroom man agement; a largely agreed facet of overall teaching quality; see for example Emmer \& Stough, 2001). Autonomy support, although out lined in the control value theory, was not included in this study due to its ambiguous and highly complex effects requiring highly specific analyses (see for example the interdependence of autonomy support and structure; Jang, Reeve, \& Deci, 2010). Further, achievement related feedback and consequences (as per control value theory) are unlikely to play an important role in our momentary (i.e. state) assessment of teaching quality; and, hence, this facet was excluded from our study.

Overall, there is currently scarce empirical evidence attesting to the relation between teaching and students' emotions. By synthe sizing two approaches to teaching quality one that explicitly fo cuses on the relations between teaching characteristics and academic emotions (the control value theory) and the other inves tigating the overall teaching quality (the process product ap proach) we focused our study on eight teaching characteristics and their relations to academic emotions.

\section{The role of domains in the relation between characteristics of teaching and students' emotions}

Previous research has shown that students experience different levels of specific emotions in different domains (e.g., Goetz, Cron jaeger, Frenzel, Lüdtke, \& Hall, 2010; Goetz, Frenzel, Hall, \& Pekrun, 2008; Goetz et al., 2006, 2007). Goetz, Frenzel, Lüdtke, and Hall (2011) present a number of possible explanations for differential levels of reported habitual emotions depending on a specific do main. First, the subject domain as such may involve varying do main value, content difficulty, as well as self concept and specific abilities related to this domain (e.g., quantitative domains of math ematics and physics vs. language domains like English). Second, classroom composition, or classroom dynamics that involve levels of competition and peer support may result in different emotion profiles in different domains (c.f., Butler, 1989). Third, classroom instruction may have a bearing on student emotions (e.g., having different teachers in different subjects who differ in emotions they show in class and their teaching style; cf., Hatfield et al., 1994; Pat rick, Hisley, \& Kempler, 2000; Wild, Enzle, \& Hawkins, 1992).

Although there is evidence attesting to the mean level differ ences in academic emotions in different domains, it remains un clear whether the strength of relations between teaching characteristics and students' emotions also differs across domains. This question is of high relevance due to at least two reasons. First, from a practical perspective teachers may benefit from knowing whether their teaching elicits emotions in students more or less strongly in some domains as opposed to others. Second, from a the oretical perspective it is important to know whether relations be tween teaching characteristics and emotions assessed in a specific domain can shed light on similar relations in other domains. How ever, we found no empirical studies examining whether structural relationships between characteristics of teaching and academic emotions or between teaching characteristics and cognitive appraisals, respectively, differ across academic domains. Goetz, Frenzel, Stoeger, and Hall's (2010) investigation represents a nota ble exception. The researchers showed that the structural relations between control/value appraisals and emotions (enjoyment, pride, and contentment) are rather stable across achievement and non achievement situations. In other words, the situational factor did not moderate the strength of relations. If structural relations are similar in such highly different contexts, they might also be similar across different subject domains (cf., Frenzel, Pekrun, \& Goetz, 2007a).

In sum, although it is reasonable to assume that there are mean level differences in academic emotions experienced across various academic domains, previous research suggests that structural relationships between characteristics of teaching and discrete emo tions may not be domain specific. For example, although students might experience higher levels of enjoyment in English classes as compared to mathematics classes (e.g., Goetz et al., 2007), the strength of relations between teacher enthusiasm and enjoyment might be similar in both domains.

\section{The current study}

Our study aims to investigate whether there are relations be tween characteristics of teaching and students' real time discrete emotions. Thus, by examining real time judgments of teaching quality and real time emotions in the classroom we go beyond pre vious investigations that focused on trait constructs of teaching and emotions. This real time approach allows for intraindividual analyses reflecting intraindividual differences in the perception of teaching quality and emotions experienced in a classroom set ting (idiographic approach; see Lamiell, 1998). To our knowledge, this is the first study using a real time approach for investigating relations between teaching characteristics and academic emotions in the classroom. Further, drawing upon recent results demonstrat ing domain specificity of classroom emotions (e.g., Goetz et al., 2007), the current study investigated both teaching quality and emotions with respect to specific subject domains and analyzed whether relations between teaching quality and emotions differ across academic domains. We focused on characteristics of teach ing that have been deemed crucial with respect to their impact on academic emotions (Pekrun, 2006). Further, we focused on a num ber of emotions that are conceptually distinct and particularly sali ent in academic settings. In line with previous research in the field of teaching we used an approach that grouped specific teaching characteristics into sub sets.

We would like to emphasize that the aim of our study was to show that real time emotions relate to teaching and that those relations are rather similar across domains. Hence, we intended to present a rather general picuture of the relations between teaching quality and emo tions in different domains using a real time approach. We formulated two main hypotheses that are depicted in Fig. 1.

Hypothesis 1. There are significant relations between teaching characteristics factors (groups of specific teaching characteristics based on an exploratory approach) and discrete emotions as assessed in real time situations on an intraindividual level in different academic domains in the classroom. Positive emotions should relate to teaching characteristics factors that are known to enhance students' experiences of control and their intrinsic value (e.g., an illustrative and enthusiastic teaching style), whereas 


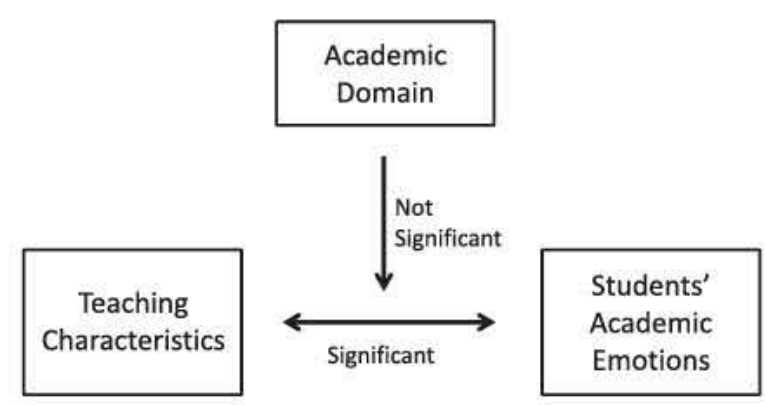

Fig. 1. Hypotheses on the role of the academic domain in the relations between teaching characteristics and students' academic emotions.

negative emotions should correspond to factors that are known to reduce levels of control (e.g., a teaching style characterized by high expectations and fast pace; see Pekrun, 2006).

Hypothesis 2. The strength of relations between real time judg ments of characteristics of teaching (as represented by teaching characteristics factors) and real time academic emotions does not significantly differ across academic domains. Although there might be clear mean level differences in both types of constructs, the structural relations can be assumed to be universal across domains (see Frenzel et al., 2007a).

\section{Method}

\subsection{Sample}

The sample consisted of 121 German students ( $50 \%$ female) from grade $8(48 \%)$ and grade $11(52 \%)$ with a mean age of 16.16 years $(S D=1.84)$. The mean age of the 8 th graders was 14.45 years $(S D=.76)$ and of the 11 th graders was 17.73 years $(S D=.88)$.

Participants were randomly selected from 41 classrooms (21 classrooms from grade 8 and 20 from grade 11) from 7 schools (school type: Gymnasium, the highest track in the three track Ger man school system; approximately one third of the total student cohort in Germany attends Gymnasium; Baumann, Schneider, Vollmar, \& Wolters, 2012). Grades were rather typical for German students of this age attending Gymnasium (see results of the PISA assessments; e.g., Prenzel et al., 2008). On a scale ranging from 1 (very good) to 6 (insufficient) mean levels were 3.15 for mathemat ics $(S D=1.04), 2.98$ for physics $(S D=1.10), 2.79$ for German $(S D=.85)$, and 2.83 for English $(S D=0.97)$. Two to four students were randomly selected from each classroom for participation in the study. Data were collected over a period of 10 school days dur ing the final three months of the academic year using the experi ence sampling method (Csikszentmihalyi \& Larson, 1987; Hektner, Schmidt, \& Csikszentmihalyi, 2007). We employed per sonal digital assistant (PDA) devices (see Supplementary 1) that were programmed with PMat software (Weiss, Beal, Lucy, \& MacDermid, 2004).

\subsection{Procedure}

In the first step of this study students completed a paper and pencil questionnaire collecting demographic information. Students were then asked to use PDAs to record their immediate emotional experiences in class. Consistent with the aim of obtaining represen tative data of individuals' experiences in four subject domains, our assessment employed a combination of event and a time random ization procedures (Hektner et al., 2007). Students were instructed to activate their PDA devices at the beginning of mathematics, phys ics, German or English class (i.e., event sampling), with each class lasting $45 \mathrm{~min}$. The device then signaled once at randomly selected time intervals (time randomization) within the next $40 \mathrm{~min}$ and showed on its display a questionnaire. Students were each asked to complete the questionnaire immediately. One question at a time was displayed and it took students approximately $13 \mathrm{~min}$ to com plete the entire assessment. Items intended to capture teaching characteristics were shown first and were then followed by items assessing emotions. Within the two blocks (teaching characteristics and emotions) items were presented in a completely randomized way for each assessment for each student. Teachers were familiar ized with the assessment protocol and they agreed to students' par ticipation in this study. The assessment took place only during regular classes and it did not interrupt exams. The 121 students completed altogether 1525 questionnaires. On average, each stu dent completed 12.60 questionnaires throughout the 10 assessment days $(S D=6.04 ; \min =1, \max =28)$. On average, $3.89(S D=2.16)$ were related to mathematics, $3.09(S D=1.80)$ were related to phys ics, $3.63(S D=2.08)$ were related to German, and $3.27(S D=1.71)$ were related to English.

\subsection{Study measures}

Consistent with other experience sampling studies focusing on emotions (e.g., Nett, Goetz, \& Hall, 2011; Tong et al., 2007) we used single item measures. The high validity of single item measures has been supported by findings from Wanous, Reichers, and Hudy (1997). In regards to the situational focus of our items we decided to refer to the specific lesson, in which teaching characteristics and academic emotions were assessed. That is, items that assessed teaching characteristics and emotions were formulated with re spect to the specific lesson, in which the assessment took place. Focusing on the whole lesson rather than "this moment" was a way to avoid reports of experiences that might be rather unrelated to teaching (e.g., high enjoyment due to a pleasant exchange with a classmate).

Teaching characteristics. As stated above, we selected eight char acteristics from Pekrun's (2006) control value theory and the general research on teaching quality. Each characteristic was assessed with a single item. The first item gauged understandability, or whether students could understand their teacher in terms of the vocabulary she or he was using ("In this lesson, our teacher's vocabulary is easy to understand"). The second item assessed the amount of illustration that teachers used when explaining the material in class ("In this lesson, our teacher explains the material in such a way that I can picture in my mind how things work"). The third item focused on teacher enthusiasm ("In this lesson, our tea cher presents the material with enthusiasm"). Fostering attention was the fourth item that gauged teacher's intent to hold students' attention ("In this lesson, our teacher makes sure that we pay attention"). The fifth item, lack of clarity, gauged how unclear teachers' instructions were ("In this lesson, our teacher's instruc tions are so unclear that I don't know what I have to do"). Difficulty (sixth item) assessed whether the material was too difficult for stu dents to understand ("What is taught in this lesson is too difficult for me"). Pace (seventh item) investigated whether pace was too fast for the students ("The pace of this lesson is too fast for me"). The eighth item assessed the level of expectation and referred to whether teacher expectations were too high for students ("What our teacher expects from us in this lesson is far too much"). Re sponse format for these items consisted of a five point Likert scale ranging from (1) strongly disagree to (5) strongly agree.

The single items for each teaching characteristic were either adopted or adapted from existing instruments (Kunter \& Baumert, 2006; Pekrun et al., 2007). For the purposes of the present 
experience sampling study, we chose single items that best repre sented each corresponding scale. The items assessing understand ability, lack of clarity, and pace were adapted from the COACTIV study (see Kunter \& Baumert, 2006); items for illustration and fos tering attention were adopted from scales employed in the PALMA study (Pekrun et al., 2007). The item assessing teacher enthusiasm was taken from the SEEQ questionnaire used in students' evalua tions of teaching effectiveness (e.g., Marsh \& Bailey, 1993). Finally, the items for difficulty and level of expectation were developed specifically for the purposes of the present study.

It is important to note that the items on teaching characteristics were formulated in a way that excluded possible curvilinear rela tions with academic emotions. For example, with respect to "diffi culty," too low and too high difficulty may result in boredom. Thus, the item on difficulty focused on one aspect, namely, the material presented during the lesson being "too difficult". Similarly, items that gauged "pace" and "level of expectation" indexed excessively high levels of these characteristics (i.e., "too fast," "expects too much.")

Emotions. Two selection criteria were used to identify emo tions to be assessed in the current study. First, we wanted to as sess academic emotions that are conceptually distinct on a phenomenological level with respect to a categorization of emo tions based on Watson's and Tellegen's (1985) circumplex mod el. This model uses dimensions of valence and activation to categorize emotions. Second, we examined research literature for discrete emotions that were particularly salient in classroom settings (see Goetz et al., 2007; Pekrun et al., 2002). After com bining these two selection criteria we decided to assess the aca demic emotions of enjoyment and pride (both positive and activating), anxiety and anger (both negative and activating), and helplessness and boredom (both negative and deactivating). We did not integrate positive deactivating emotions (e.g. relief, relaxation, nostalgia) because these emotions tend to occur after as opposed to during academic situations (see Pekrun et al., 2002). Thus, such emotions would have been inappropriate for our real time assessment. The intensity of emotions of enjoy ment, pride, anxiety, anger, helplessness, and boredom were as sessed by the item "How much [EMOTION] are you experiencing during this class?" (for a similar assessment see Goetz, Bieg, Lüdtke, Pekrun, \& Hall (in press)). Response format for these items consisted of a five point Likert scale ranging from (1) not at all to (5) very strongly.

\subsection{Data analysis}

Our data represent a two level structure, with measures (Level $1 ; N=1525$ ) nested within persons (Level 2; $N=121$ ). ${ }^{1}$ To account for the fact that our data are not independent of each other within persons multilevel analyses were conducted using the programs Mplus 5.2 (Muthén \& Muthén, 2008) and HLM 6.08 (Hierarchical Lin ear Modeling; Raudenbush \& Bryk, 2002; Raudenbush, Bryk, \& Cong don, 2009).

In the first step we aimed to group the eight teaching character istics into factors (see Walberg, 1990) based on a multilevel explor atory factor analysis (MFA; using Mplus 6.1 software; applying an oblique, geomin rotation). This approach has been successfully em ployed in a number of studies that focused on groups of teaching characteristics, instead of focusing on single ones (see Feldman, 2007; Hugener et al., 2009; Kunter \& Baumert, 2006; Marsh, 1982, 1987, 2007; Murray, 1983; Seidel \& Shavelson, 2007). The rationale for using higher order factors representing teaching qual

\footnotetext{
${ }^{1}$ We took the third level (students within classrooms) not into account as only two to four students were randomly selected from each classroom.
}

ity rather than using the eight single teaching characteristics was twofold. Firstly, previous research has shown that higher order fac tors or high inferential measures of teaching quality usually have a higher predictive power for student outcomes (e.g., achievement) than low inferential measures (e.g., Fraser \& Walberg, 1981). Sec ondly, as our eight teaching characteristics were each assessed with a single item, higher order factors could be assumed to have higher reliability than their respective single item indicators. For the MFA, we requested factor solutions on the within level with an unrestricted solution on the between level, so that our factors encompassing teaching characteristics would reflect how strongly the event ratings can be predicted by the extracted latent factors indicating differences and similarities in those ratings (see for example Reise, Ventura, Nuechterlein, \& Kim, 2005).

In the next step, multilevel regression models were run with academic emotions as dependent variables and teaching characteristics factors as independent variables (using HLM 6.08 software). The teaching characteristics factors were now represented as mean values (not standardized) of the respec tive single items pertaining to the MFA factors and were group mean centered (here: person centered) for the analyses. With respect to subject domain differences in intercepts we constructed three dummy variables for physics, German, and English, with mathematics representing the reference domain (e.g., dummy physics: mathematics $=0$, physics $=1$, German $=0$, English $=0$ ). Thus, due to the coding of the dummy variables in our multilevel regression analysis the intercept refers to the reference domain (i.e., mathematics). Further, the three subject dummy variables show the degree to which the inter cept differs from that of mathematics (reference domain) in the three other subject domains.

With respect to domain related differences in slopes three interaction terms were built between the independent variable (factors) and the three dummy variables (e.g., physics $\times$ factor 1) for each of our models. Thus, in our multilevel analysis the slope refers to the effect in the domain of mathematics (refer ence domain) and the three interaction terms show how the slopes differ from those of mathematics (reference domain) in the three other subject domains. Interaction terms were created by multiplying group mean centered factors by their respective dummies (the interaction terms were not re centered). Our regression models each represent random coefficient regression models.

\section{Results}

\subsection{Preliminary analysis}

Table 1 shows descriptive statistics for teaching characteristics and students' academic emotions for the four academic domains of mathematics, physics, German, and English. It also shows whether mean level differences between subject domains are significant (the right side of Table 1 ). In regards to mean level differences in both teaching characteristics and academic emotions, the language domains show an overall more positive picture than the quantita tive domains (e.g., higher levels of understandability and enjoy ment for the language domains). For academic emotions, mean levels were more similar across academic domains. Due to the fact that academic emotions were assessed with items of virtually identical wording (the actual emotion was the only thing that dif fered), mean levels across emotions can be directly compared. The by far highest mean levels were found for boredom (around $M=3$, which is the midpoint of the 5 point Likerts scale), followed by enjoyment and other emotional experiences assessed in the study (i.e., anger, helplessness, pride, anxiety). Zero order intercorrela 
Table 1

Descriptive statistics for teaching characteristics and students' academic emotions.

\begin{tabular}{|c|c|c|c|c|c|c|c|c|c|c|c|c|c|c|c|c|}
\hline & \multicolumn{2}{|l|}{ All } & \multicolumn{2}{|c|}{ Mathematics [M] } & \multicolumn{2}{|c|}{ Physics [P] } & \multicolumn{2}{|c|}{ German $[G]$} & \multicolumn{2}{|c|}{ English $[\mathrm{E}]$} & \multicolumn{6}{|c|}{ Significance of mean level differences between subject domains } \\
\hline & $M$ & $S D$ & $M$ & $S D$ & $M$ & $S D$ & $M$ & $S D$ & $M$ & $S D$ & MP & MG & ME & PG & PE & GE \\
\hline \multicolumn{17}{|c|}{ Teaching characteristics } \\
\hline Understandability & 3.30 & 1.38 & 3.18 & 1.36 & 2.96 & 1.37 & 3.51 & 1.39 & 3.49 & 1.32 & - & ** & * & **** & *** & - \\
\hline Illustration & 3.03 & 1.37 & 2.87 & 1.35 & 2.83 & 1.37 & 3.21 & 1.36 & 3.17 & 1.35 & - & $* *$ & - & * & - & * \\
\hline Enthusiasm & 2.85 & 1.37 & 2.86 & 1.35 & 2.60 & 1.43 & 3.03 & 1.35 & 2.86 & 1.34 & * & - & - & ** & - & - \\
\hline Fostering Attention & 3.04 & 1.39 & 3.02 & 1.36 & 2.94 & 1.47 & 3.02 & 1.38 & 3.18 & 1.35 & _- & _ & - & - & _- & _- \\
\hline Lack of clarity & 1.83 & 1.20 & 1.93 & 1.22 & 1.92 & 1.17 & 1.80 & 1.27 & 1.69 & 1.11 & - & $*$ & $* *$ & - & $*$ & - \\
\hline Difficulty & 1.83 & 1.14 & 2.26 & 1.26 & 2.04 & 1.23 & 1.48 & 0.91 & 1.55 & 0.92 & ** & **** & **** & $* * *$ & **** & - \\
\hline Pace & 1.72 & 1.08 & 2.07 & 1.22 & 1.87 & 1.11 & 1.42 & 0.86 & 1.53 & 0.95 & * & $* * *$ & $* * *$ & $* * *$ & $* * *$ & - \\
\hline Level of expectation & 1.84 & 1.12 & 2.03 & 1.18 & 1.97 & 1.12 & 1.66 & 1.07 & 1.69 & 1.06 & - & $* * *$ & **** & *** & $*$ & - \\
\hline \multicolumn{17}{|l|}{ Academic emotions } \\
\hline Enjoyment & 2.34 & 1.32 & 2.18 & 1.29 & 2.26 & 1.30 & 2.43 & 1.34 & 2.51 & 1.34 & - & * & **** & * & $* *$ & - \\
\hline Pride & 1.66 & 1.07 & 1.66 & 1.08 & 1.61 & 1.02 & 1.63 & 1.07 & 1.75 & 1.12 & - & - & - & - & $*$ & * \\
\hline Anxiety & 1.42 & 0.95 & 1.53 & 1.06 & 1.42 & 0.95 & 1.33 & 0.84 & 1.39 & 0.91 & - & * & - & - & - & - \\
\hline Anger & 1.77 & 1.19 & 1.85 & 1.25 & 1.86 & 1.24 & 1.69 & 1.16 & 1.71 & 1.13 & - & - & ${ }^{*}$ & - & - & - \\
\hline Helplessness & 1.68 & 1.13 & 1.95 & 1.31 & 1.75 & 1.16 & 1.43 & 0.90 & 1.58 & 1.05 & & *** & **** & **** & * & - \\
\hline Boredom & 3.06 & 1.45 & 3.01 & 1.44 & 3.09 & 1.55 & 3.03 & 1.49 & 3.12 & 1.34 & _- & _- & _- & _- & _- & _- \\
\hline
\end{tabular}

Note: "Difficulty", "pace", and "level of expectation" indexed excessively high levels of these characteristics. Response formats were 1 (strongly disagree) to 5 (strongly agree) for teaching characteristics and 1 (not at all) to 5 (very strongly) for academic emotions (intensity). $N_{\text {all }}=1525 ; n_{\text {Mathematics }}=436 ; n_{\text {Physics }}=302 ; n_{\text {German }}=405 ; n_{\text {English }}=382$.

${ }^{* *} p<.05$.

*** $p<.001$.

tions among teaching characteristics are shown in Appendix A and those among emotion measures in Appendix B (each referring to measures across all domains). Correlations between the eight teaching characteristics and discrete academic domains both across and within domains are shown in Supplementary 2.

To examine variance in teaching characteristics and discrete academic emotional experiences at the within and between stu dent level we used a fully unconditional model. If a student gave similar responses across all real time assessments, the proportion of variance at the within student level would be rather low and on the between student level rather high. Consequently, intraclass correlations would be expected to be high. Conversely, a strong variability in responses across assessments would be reflected in a large proportion of variance at the within student level and a small proportion at the between student level. In that case intra class correlations would be rather weak. The results of our study reveal rather low intraclass correlations for both academic emo tions and teaching characteristics ranging from .074 to .187 (see Appendix C). Thus, our findings show a rather strong variation in the real time within person assessments. In other words, both judgments of teaching characteristics and self reports of levels of academic emotions strongly differed across real time assessments within students. It is important to note that all assessments within each student were taken into account in these analyses. Thus, the variance of constructs both within and across the four academic domains is part of the within person variance.

\section{Main analyses}

Multilevel exploratory factor analysis. Table 2 shows results of the multilevel exploratory factor analysis (MFA) on the within person level (Level 1). We used the Bayesian Information Criterion to determine the optimal number of factors (BIC; Schwarz, 1978). It accounts both for the log likelihood of a model, the number of model parameters, and sample size (Nylund, Nishina, Bellmore, \& Graham, 2007). The BIC provides relative information with respect to different models, with lower BIC indicating a better model fit. Furthermore, we used the Comparative Fit Index (CFI; cutoff: $>.95$ ) as an incremental fit index and the root mean square error of approximation (RMSEA; cutoff: <.05) as an absolute fit index for evaluating model fit (Hu \& Bentler, 1999). Also, in determining the optimal factor solution, interpretability of the factors was ta ken into account.

The fit indices for the MFA as outlined in Table 2 clearly indicate a two factor solution based on the above mentioned fit indices (BIC, CFI, RMSEA). ${ }^{2}$ This factor analysis was done across academic domains with analyses within domains showing the same factor structure (see Supplementary 3). The factor loadings of the two fac tor solution are shown in Table 3. Factor 1 includes the teaching characteristics of understandability, illustration, enthusiasm, and fostering attention, and factor 2 includes the teaching characteristics of lack of clarity, difficulty, pace, and level of expectation. Table 3 shows factor loadings of the two factor solution with altogether low side loadings (all below .30). The loadings as outlined in Table 3 show that the eight items indexing teaching characteristics were clearly arranged into the two factors. Based on the items loading on the respective factors, we interpreted factor 1 as characteristics of teaching that facilitate learning (by presenting content in a highly understandable, illustrative, and enthusiastic way while making sure that students pay attention). Factor 2 refers to the nature of the con tent itself, and indexes whether the content was unclear (lack of clarity) and too difficult due to both qualitative reasons (difficulty) and quantitative reasons (pace, level of expectation). We label factor 1 as supportive presentation style and factor 2 as excessive lesson de mands. The correlation between the two factors was $r=.30$ $(p<.001)$ indicating that they share some common variance $(9 \%)$ but are rather independent from each other. The intraclass correla tions of both factors are rather low, namely .225 for factor 1 and .133 for factor 2 (see Appendix C for variance components) indicat ing a strong proportion of within person variance of the two factors. In other words, across all measures within persons (including across domains) the perception of characteristics of teaching strongly fluc tuates within students. Both factors showed acceptable reliabilities of $\alpha=.79$ for factor 1 and $\alpha=.78$ for factor 2 (Cronbach's alpha, cal culated across all assessments).

\footnotetext{
${ }^{2}$ More detailed analyses on the three-factor solution support the superiority of the two-factor solution. The three-factor solution mainly reflects the two factor-solution with the exception that one item of Factor 1 additionally loads on a third factor. The loading on the third factor, however, is significantly lower than the loading of this item on factor 1. Further, and also in support of the two-factor solution, the eigenvalue of the third factor is clearly below $1(0.68)$.
} 
Table 2

Fit indices for exploratory factor analyses on within level.

\begin{tabular}{llrlll}
\hline Factor solutions & $\chi^{2}$ & $d f$ & CFI & RMSEA & BIC \\
\hline 1 Factor & 1218.525 & 20 & .652 & .117 & 36638.370 \\
2 Factors & 27.454 & 13 & .996 & .000 & 35498.528 \\
3 Factors & 13.900 & 7 & .998 & .000 & 35528.886 \\
\hline
\end{tabular}

Note: Each analysis accounted for the hierarchical structure of the study data (measures within persons), that is, the factors were modeled only on the within level with an unrestricted model on the between level. Oblique, geomin rotation was applied. Level 1: $N=1510$; Level 2: $N=121$.

Table 3

Factor loadings for the two-factor solution.

\begin{tabular}{lcl}
\hline $\begin{array}{l}\text { Teaching } \\
\text { characteristics }\end{array}$ & $\begin{array}{l}\text { Factor 1 (supportive } \\
\text { presentation style) }\end{array}$ & $\begin{array}{l}\text { Factor 2 (excessive lesson } \\
\text { demands) }\end{array}$ \\
\hline Understandability & .799 & -.008 \\
Illustration & .669 & -.022 \\
Enthusiasm & .672 & .071 \\
Fostering & .562 & .226 \\
$\quad$ attention & & \\
Lack of clarity & -.271 & .455 \\
Difficulty & .001 & .714 \\
Pace & .054 & .702 \\
Level of & -.064 & .722 \\
$\quad$ expectation & & \\
\hline
\end{tabular}

Note: "Difficulty", "pace", and "level of expectation" indexed excessively high levels of these characteristics. For every teaching characteristic, the higher factor loading was always highly significant $(p<.001)$.

Multilevel regressions. For our random coefficient regression models, we included dummy variables, both teaching quality fac tors, and their respective interaction terms simultaneously. ${ }^{3}$ Table 4 shows the results of multilevel regressions of state academic emo tions on the two teaching characteristics factors. In these analyses both factors are taken simultaneously into account and thus show effects of each factor when the other factor is controlled for. ${ }^{4}$ Dum my variables (values of 0 or 1 for the academic domains) were in cluded in the models, with the intercept representing the mean level in mathematics (mathematics as a reference domain was al ways represented by the dummy value of 0 ) and coefficients of the respective dummies showing how the intercept in the respective do main differs from the mean level in mathematics. The highest inter cept is found for boredom and the lowest for anxiety indicating that in the domain of mathematics boredom is the most intense emotion, whereas anxiety is a less intense emotion experienced by students. There are only two of altogether 18 ( $=6$ emotions $\times 3$ domain dum mies) differences in mean levels of emotions across domains as indi cated by the significant values of the domain dummies (see also Table 1 for descriptive statistics on mean levels of emotions in the four academic domains). In other words, emotions experienced in the domains of physics, German, and English are rather similar in their intensity to those experienced in mathematics.

In regards to the effects of teaching characteristics on academic emotions for factor 1 (supportive presentation style) as indicated by the slopes the analyses revealed significant positive coefficients for

\footnotetext{
${ }^{3}$ Our regression model represents a random coefficients regression models with the level 1 equation being as follows: $Y_{i j} \beta_{0 j}+\beta_{1 j}$ physics $s_{i j}+\beta_{2 j}$ German $_{i j}+\beta_{3 j}$ English $_{i j}$ [dummy variables $]+\beta_{4 j} F 1_{i j}[$ teaching characteristics factor 1$]+$ $\beta_{5 j} F 2_{i j}[$ teaching characteristics factor 2$]+\beta_{6 j}\left(\right.$ physics $\left._{i} j \times F 1_{i j}\right)+\beta_{7 j}\left(\operatorname{German}_{i j} \times F 1_{i j}\right)+$ $\beta_{8 j}\left(\right.$ English $\left._{i j} \times F 1_{i j}\right)$ [interaction terms factor 1$]+\beta_{9 j}\left(\right.$ physics $\left._{i j} \times F 2_{i j}\right)+\beta_{10 j}\left(\right.$ German $_{i j} \times$ $\left.F 2_{i j}\right)+\beta_{11 j}\left(\right.$ English $\left._{i j} \times F 2_{i j}\right)$ [interaction terms factor 2$]+r_{i j}$. For the regression models where each teaching factor is considered separately, the respective equations for level 1 are each reduced by the predictor of the other teaching factor and its corresponding interaction terms.

${ }^{4}$ Including academic achievement as a covariate in the analyses does not change the pattern of results (see Supplementary 5).
}

enjoyment $(b=0.38)$ and pride $(b=0.28)$, and a negative coefficient for boredom $(b=0.19)$. No single interaction term reached statis tical significance. In other words, supportive presentation style was positively related to levels of enjoyment and pride, and negatively to boredom, and the strength of those relations in the domains of physics, German, and English was very similar to that in mathematics.

As for factor 2 (excessive lesson demands) there were significant effects on all emotions with negative coefficients for enjoyment $(b=0.30)$ and pride $(b=0.14)$, and positive coefficients for anx iety $(b=0.48)$, anger $(b=0.46)$, helplessness $(b=0.74)$, and bore dom $(b=0.37)$. Three of the altogether 18 interaction terms reached significance, namely two with respect to anxiety $(b=0.33$ for German $\times \mathrm{F} 2, b=0.29$ for English $\times \mathrm{F} 2)$ and one with respect to helplessness ( $b=0.45$ for English $\times$ F2). Thus, the impact of the factor excessive lesson demands on anxiety is less strong for German and English as compared to mathematics (refer ence domain) and its impact on helplessness is less strong for Eng lish as compared to mathematics.

Rather similar results were found when we conducted analyses, in which both factors were taken separately into account (see Supplementary 4). The pattern of the results differed from those outlined above in that the effects of factor 1 (supportive presenta tion style) on anger and helplessness were significant.

Our results indicate that both factors have a unique contribu tion to the levels of the positive emotions of enjoyment and pride and the negative emotion of boredom, with factor 2 being the most important predictor of the negative emotions of anxiety, anger, and helplessness. ${ }^{5}$ Our models that simultaneously included both factors explained $2545 \%$ of the variance in students' academic emotions (median of the explained variance across the 6 models: 36\%).

\section{Discussion}

The current study investigated links between characteristics of teaching and student academic emotions across four academic do mains by adopting a real time approach (i.e., experience sampling). Consistent with our first hypothesis, we found significant relations between characteristics of teaching and students' discrete emo tions in four different academic domains. The second hypothesis stating that the strength of relations between characteristics of teaching and academic emotions was rather similar across aca demic domains was also supported.

\section{Relations between characteristics of teaching and academic emotions}

Results of our multilevel factor analysis, where factor solutions were requested exclusively on the within level, showed that eight teaching characteristics could be described by two latent factors of teaching characteristics (cf., other approaches focusing on groups of teaching characteristics; e.g., Feldman, 2007; Hugener et al., 2009; Kunter \& Baumert, 2006; Marsh, 1982, 1987, 2007; Murray, 1983; Seidel \& Shavelson, 2007). We labeled the factor consisting of understandability, illustration, enthusiasm, and fostering atten tion as supportive presentation style and the factor consisting of lack of clarity, difficulty, pace, and level of expectation as excessive lesson demands. The factor supportive presentation style represents teaching characteristics related to the way, in which the material is presented in class, relatively independent from its requirements.

\footnotetext{
${ }^{5}$ We ran further analyses for evaluating whether domain or instructional method has a stronger impact on emotions (see Supplementary 6). The average variance (across all 6 emotions) explained by $\mathrm{F} 1 / \mathrm{F} 2$ is $12.66 \%$, whereas those for subject domains is $6.66 \%$. Thus, the impact of teaching on academic emotions is clearly stronger than those of the subject domains.
} 
Table 4

Academic emotions predicted by both factors of teaching characteristics (supportive presentation style and excessive lesson demands).

\begin{tabular}{|c|c|c|c|c|c|c|c|c|c|c|c|c|}
\hline \multirow[t]{2}{*}{ Predictors } & \multicolumn{2}{|c|}{ Enjoyment } & \multicolumn{2}{|l|}{ Pride } & \multicolumn{2}{|l|}{ Anxiety } & \multicolumn{2}{|l|}{ Anger } & \multicolumn{2}{|c|}{ Helplessness } & \multicolumn{2}{|c|}{ Boredom } \\
\hline & $b$ & $S E$ & $b$ & $S E$ & $b$ & $S E$ & $b$ & $S E$ & $b$ & $S E$ & $b$ & $S E$ \\
\hline Intercept & $2.29^{* * *}$ & .08 & $1.73^{* * *}$ & .07 & $1.38^{* * *}$ & .05 & $1.69^{* * *}$ & .07 & $1.70^{* * * *}$ & .07 & $2.82^{* * * *}$ & .09 \\
\hline Slope F1 (Supp. Pres. Style) & $0.38^{* * *}$ & .07 & $0.28^{* * * *}$ & .06 & 0.02 & .04 & -0.14 & .06 & -0.10 & .06 & $-0.19^{*}$ & .08 \\
\hline Slope F2 (Exc. Less. Dem.) & $-0.30^{* * *}$ & .07 & $-0.14^{* *}$ & .05 & $0.48^{* * *}$ & .07 & $0.46^{* * *}$ & .07 & $0.74^{* * * *}$ & .08 & $0.37^{* * * *}$ & .07 \\
\hline Dummies: Physics & -0.02 & .10 & -0.13 & .09 & -0.02 & .07 & 0.04 & .09 & -0.01 & .07 & 0.26 & .13 \\
\hline German & 0.04 & .09 & -0.14 & .08 & -0.03 & .06 & 0.09 & .10 & -0.13 & .07 & $0.32^{*}$ & .13 \\
\hline English & 0.10 & .10 & 0.03 & .08 & -0.01 & .06 & 0.02 & .08 & -0.08 & .07 & $0.36^{* *}$ & .11 \\
\hline Interactions: Physics $\times F 1$ & 0.06 & .10 & -0.08 & .08 & -0.02 & .07 & -0.08 & .10 & 0.09 & .08 & 0.12 & .12 \\
\hline German $\times F 1$ & 0.01 & .10 & -0.08 & .07 & -0.03 & .06 & -0.06 & .09 & 0.08 & .07 & -0.26 & .14 \\
\hline English $\times F 1$ & 0.04 & .10 & -0.14 & .09 & -0.01 & .06 & -0.01 & .08 & 0.06 & .07 & -0.01 & .11 \\
\hline Physics $\times$ F2 & 0.23 & .11 & 0.13 & .08 & -0.24 & .10 & -0.09 & .11 & -0.16 & .11 & 0.01 & .10 \\
\hline German $\times$ F2 & 0.23 & .11 & 0.14 & .08 & $-0.33^{* *}$ & .09 & -0.12 & .11 & -0.25 & .10 & -0.15 & .13 \\
\hline English $\times F 2$ & -0.10 & .10 & 0.05 & .10 & $-0.29^{* *}$ & .10 & -0.14 & .11 & $-0.45^{* * *}$ & .11 & 0.00 & .11 \\
\hline$R^{2}$ & .33 & & .25 & & .27 & & .42 & & .45 & & .39 & \\
\hline
\end{tabular}

Note: The two factors of teaching characteristics, their interaction terms as well as the subject-dummies were all entered simultaneously in the multilevel regression model. Thereby, factors 1 and 2 were group-mean centered, dummies were uncentered, and the interaction terms were calculated with the group-mean centered factors 1 and 2 and the respective dummies and (not re-centered afterwards). $R^{2}$ refers to the explained variance on Level 1.

$p<.05$.

*** $p<.01$.

$p<.001$.

The second factor represents specific course requirements with high levels of this factor indexing the state of being overchallenged.

In line with our hypothesis we found clear relations between characteristics of teaching as represented by the two factors (sup portive presentation style, excessive lesson demands) and aca demic emotions. When using each of the two factors separately to predict emotions, supportive presentation style was positively re lated to enjoyment and pride and negatively related to anger, help lessness, and boredom. However, it was not related to anxiety. From an appraisal perspective this teaching pattern might indi rectly affect emotions by enhancing intrinsic value appraisals (through understandability, illustration, enthusiasm) and control appraisals (through understandability, illustration, fostering atten tion) in students and further, might more directly impact emotions due to its affective component (enthusiasm). Thus, high intrinsic value and high control appraisals combined with enthusiastic teaching can clearly be assumed to foster enjoyment and pride in students and reduce anger, helplessness, and boredom. Concerning anxiety, the non significant relation with supportive presentation style certainly makes sense: It is possible that high control reduces anxiety, whereas value enhances anxiety (e.g., worry cognitions re lated to receiving bad achievement outcomes in a domain which is judged as being highly important; c.f., Haag \& Goetz, 2012). In combination, these positive and negative effects of supportive pre sentation style on anxiety might reverse each other resulting in a non significant relation between this factor and anxiety.

The second factor, labeled excessive lesson demands, was nega tively related to enjoyment and pride and positively related to anx iety, anger, helplessness, and boredom. From an appraisal perspective the characteristics that comprise this factor might indirectly affect emotions by reducing control appraisals in stu dents. In line with this interpretation, the relation between exces sive lesson demands and helplessness were very high $(b=0.74$; when factor 1 is also taken into account). Research in the field of learned helplessness (Seligman, 1975) has shown that subjectively uncontrollable situations led to helplessness (e.g. Burger \& Arkin, 1980).

Our analyses that took both factors as predictors of academic emotions into account revealed that both teaching characteristics factors were related to the positive emotions of enjoyment and pride but the excessive lesson demands factor was crucial with re spect to levels of anxiety, anger, and hopelessness. Thus, the loss of control associated with higher values on excessive lesson de mands (factor 2) appears to be more important with respect to neg ative emotional experiences than the gain of control due to high levels of supportive presentation style (factor 1 ).

In sum, our study revealed significant relationships between characteristics of teaching and emotions with both constructs as sessed in real life situations via experience sampling. It is impor tant to note, that this relations were found on the intraindividual level. In this respect, our study goes beyond previous trait assess ments that did not examine patterns within students (c.f., ecolog ical fallacy, Hox, 2010; Valsiner, 1986).

\section{The role of the domain in the relations between characteristics of teaching and academic emotions}

In line with our hypothesis, the strength of intraindividual rela tions between characteristics of teaching and academic emotions did not differ across domains. The notable exception was the rela tion between excessive lesson demands and the two emotions of anxiety and helplessness. These relationships were significantly weaker for the language domains (German and English with re spect to anxiety; English with respect to hopelessness) as com pared to mathematics. A possible explanation for this result might be that the loss of control due to the high instructional con tent requirements may lead to negative emotions for mathematics, as the level of perceived difficulty is rather high in this domain (i.e., high baseline of difficulty makes high course requirements more salient for negative emotions; see Haag \& Goetz, 2012). As com pared to anger and boredom, anxiety and hopelessness might more strongly be related to achievement outcomes. This contingency may make both emotions more sensitive with respect to the effects of domains in which achievement is judged as being highly impor tant (i.e., mathematics).

In sum, with very few exceptions, the relations between pat terns of teaching and academic emotions were rather similar across academic domains. This result is in line with assumptions on the universality of structural relationships of psychosocial con structs (Frenzel et al., 2007a; Pekrun, 2006). Thus, independently of teaching in verbal vs. quantitative domains, characteristics of teaching seem to play a crucial role with respect to students' emo tions. If our results had shown that the relations between charac teristics of teaching and emotions strongly differed across domains, researchers and educators would have to take into ac count the fact that specific teaching methods were differentially 
related to students' emotions depending on the specific subject do main. Thus, while studies that examine mean levels of teaching attributes and academic emotions might take different domains into account, studies on structural relationships between the two constructs might focus on one specific domain and generalizations to other domains would be warranted.

\section{Study limitations}

Although our study allows for interpreting relations between characteristics of teaching and academic emotions in terms of intraindividual functioning, those relations cannot be interpreted in a causal way. Future studies may investigate the causality of those relations. For example, experimental studies may manipulate characteristics of teaching and investigate the impact of this manipulation on students' academic emotions.

Second, there was a rather low intraclass correlation for both academic emotions and teaching characteristics indicating a strong intraindividual variation. We did not focus on the amount of this intraindividual variability and its relations with teaching charac teristics. Future studies might integrate intraindividual variability as a variable in the analyses.

A third limitation is that we did not investigate why character istics of teaching relate to academic emotions. Viewing character istics of teaching as antecedents of academic emotions, future studies may investigate cognitive appraisals (e.g., subjective con trol, different types of subjective value, like intrinsic or extrinsic value, and expectations of others) and analyze possible mediation assumptions (e.g., relation between teaching characteristics and emotion as mediated by appraisals). However, due to the large number of variables necessary for such analyses (teaching charac teristics, emotions, cognitive appraisals) such studies might focus on one specific domain and carry out an in depth analyses of char acteristics of teaching/academic emotions relations.

A fourth limitation of our study is that we exclusively relied on self report data. Although we used a highly elaborated and ecolog ically valid real time assessment method, experience sampling is still a self report method. Even real time self reports might have been impacted by beliefs about "typical" teachers and "typical" characteristics of teaching in specific domains as well as "typical" emotions as experienced in those domains. Thus, relations be tween characteristics of teaching and emotions might to a certain (but presumably small) degree have reflected subjective beliefs on those constructs. Future studies might assess such beliefs by including them as control variables in the analyses. Further, in re gards to teaching characteristics, future studies might combine real time assessments with observations of teaching by experts and relate more objective criteria of teaching characteristics to stu dents' academic emotions. Although self report appears to be the best method available for the assessment of academic emotions (see for example, Zeidner, 1998), future studies might utilize other methods, such as physiological measurement, neuroimaging, and analysis of postural and facial expression of academic emotions. However, some of those methods might be difficult to implement in the classroom.

Fifth, single item measures were used in our study due to con straints of an experience sampling approach. Concerning teaching characteristics, the use of single item measures might have had an impact on the number of factors we found in our exploratory factor analyses. Future studies might take this shortcoming into ac count by using multiple item scales (e.g., by focusing on a reduced number of constructs in order to restrict the number of items).

Finally, in our study we referred to core subject domains exclu sively. Future studies might also investigate relations between characteristics of teaching and academic emotions in subsidiary domains.

\section{Conclusion and implications}

Consistently with previous results of trait assessments, our real time state assessment revealed relations between characteristics of teaching and academic emotions. Thus, for a specific student his or her perception of teaching characteristics is related to his or her emotional experiences. This result goes beyond previous studies using a trait approach and allowing only conclusions at the inter individual level. Our findings are important for educators because they clearly demonstrate that specific characteristics of teaching relate to students' emotions. While both supportive presentation style and excessive lesson demands were found to be important with respect to students' positive emotions (enjoyment, pride), high lev els of excessive lesson demands appear to be most critical for the negative emotions of anxiety, anger, and helplessness with the lat ter increasing if values on excessive lesson demands are rather high. Hence, in an attempt to reduce the intensity of negative emotions, educators should be encouraged to make sure that the pace of the lesson, the expectations and instructions communicated to stu dents, as well as the difficulty of the material are commensurate with students' academic preparation and the context of the class. To ensure that, special professional development activities can be introduced to help educators to better align their specified lesson requirements with students' readiness to follow them.

The results of our study also demonstrated that characteristics of teaching were related to students' emotions in a rather similar way across academic domains. Hence, our results may inform edu cators that their way of teaching may elicit various emotions in students independently of specific domains.

With respect to mean levels for both teaching characteristics and academic emotions, the language domains (German, English) showed an overall more positive pattern than the quantitative do mains (mathematics, physics). These findings may suggest that educators should be encouraged to try and enhance specific teach ing characteristics in the quantitative domains, such as increasing understandability in class by introducing new specific vocabulary in more detail or using more applied examples and illustrations when presenting complex material. The results of the current study can be incorporated into teacher preparation courses or pro fessional development seminars to raise educators' awareness of the strong link between their teaching and students' emotions. In view of the fact that emotions are strong predictors of a number of meaningful academic outcomes, the importance of this contin gency becomes even more apparent.

\section{Appendix A.}

See Table A1.

\section{Appendix B.}

See Table B1.

\section{Appendix C.}

See Table C1.

\section{Appendix D. Supplementary material}

Supplementary data associated with this article can be found, in the online version, at http://dx.doi.org/10.1016/j.cedpsych. 2013.08.001. 
Table A1

Within-level bivariate intercorrelations of teaching characteristics across all subject domains.

\begin{tabular}{|c|c|c|c|c|c|c|c|c|}
\hline & $(1)$ & $(2)$ & (3) & $(4)$ & (5) & (6) & $(7)$ & $(8)$ \\
\hline (1) Understandability & 1.00 & & & & & & & \\
\hline (2) Illustration & $.56^{* * *}$ & 1.00 & & & & & & \\
\hline (3) Enthusiasm & $.54^{* * * *}$ & $.45^{* * * *}$ & 1.00 & & & & & \\
\hline (4) Fostering attention & $.40^{* * *}$ & $.36^{* * * *}$ & $.34^{* * * *}$ & 1.00 & & & & \\
\hline (5) Lack of clarity & $-.35^{* * *}$ & $-.29^{* * *}$ & $-.23^{* * *}$ & -.12 & 1.00 & & & \\
\hline (6) Difficulty & $-.17^{* * *}$ & $-.19^{* * *}$ & $-.09^{* *}$ & .02 & $.37^{* * *}$ & 1.00 & & \\
\hline (7) Pace & $-.14^{* * *}$ & $-.15^{* * *}$ & -.07 & $.10^{* *}$ & $.38^{* * *}$ & $.53^{* * * *}$ & 1.00 & \\
\hline (8) Level of expectation & $-.25^{* * *}$ & $-.19^{* * *}$ & $-.14^{* * *}$ & -.01 & $.45^{* * *}$ & $.56^{* * *}$ & $.51^{* * *}$ & 1.00 \\
\hline
\end{tabular}

Note: "Difficulty", "pace", and "level of expectation" indexed excessively high levels of these characteristics.

*** $p<.01$.

$p<.001$.

Table B1

Within-level bivariate intercorrelations of state academic emotions across all subject domains.

\begin{tabular}{|c|c|c|c|c|c|c|c|}
\hline & & (1) & $(2)$ & (3) & (4) & (5) & (6) \\
\hline (1) & Enjoyment & 1.00 & & & & & \\
\hline (2) & Pride & $.44^{* * * *}$ & 1.00 & & & & \\
\hline (3) & Anxiety & $-.13^{* * *}$ & .02 & 1.00 & & & \\
\hline (4) & Anger & $-.17^{* * * *}$ & .01 & $.33^{* * *}$ & 1.00 & & \\
\hline (5) & Helplessness & $-.19^{* * * *}$ & -.08 & $.46^{* * *}$ & $.41^{* * *}$ & 1.00 & \\
\hline (6) & Boredom & $-.19^{* * * *}$ & $-.14^{* * * *}$ & .07 & $.32^{* * * *}$ & $.22^{* * * *}$ & 1.00 \\
\hline
\end{tabular}

$p<.001$

Table C1

Variance components and proportion of within-person variability.

\begin{tabular}{|c|c|c|c|c|c|}
\hline & \multicolumn{2}{|c|}{ Within-student variance } & \multicolumn{2}{|c|}{ Between-student variance } & \multirow[t]{2}{*}{ Intraclass-correlation } \\
\hline & $\sigma^{2}$ & $S E$ & $\tau_{00}$ & $S E$ & \\
\hline \multicolumn{6}{|l|}{ Teaching characteristics (single-items) } \\
\hline Understandability & 1.545 & 0.076 & 0.356 & 0.060 & .187 \\
\hline Illustration & 1.596 & 0.070 & 0.267 & 0.050 & .143 \\
\hline Enthusiasm & 1.546 & 0.071 & 0.333 & 0.055 & .177 \\
\hline Fostering attention & 1.585 & 0.079 & 0.339 & 0.070 & .177 \\
\hline Lack of clarity & 1.268 & 0.081 & 0.178 & 0.040 & .128 \\
\hline Difficulty & 1.181 & 0.068 & 0.120 & 0.033 & .092 \\
\hline Pace & 1.079 & 0.064 & 0.086 & 0.028 & .074 \\
\hline Level of expectation & 1.148 & 0.069 & 0.114 & 0.026 & .090 \\
\hline \multicolumn{6}{|l|}{ Teaching characteristics (factors) } \\
\hline [F1] Supportive presentation style & 0.898 & 0.054 & 0.261 & 0.045 & .225 \\
\hline [F2] Excessive lesson demands & 0.685 & 0.043 & 0.105 & 0.025 & .133 \\
\hline \multicolumn{6}{|l|}{ Academic emotions } \\
\hline Enjoyment & 1.511 & 0.076 & 0.232 & 0.045 & .133 \\
\hline Pride & 0.984 & 0.068 & 0.175 & 0.036 & .151 \\
\hline Anxiety & 0.821 & 0.075 & 0.074 & 0.016 & .083 \\
\hline Anger & 1.239 & 0.081 & 0.196 & 0.033 & .137 \\
\hline Helplessness & 1.084 & 0.073 & 0.197 & 0.041 & .154 \\
\hline Boredom & 1.849 & 0.089 & 0.273 & 0.065 & .129 \\
\hline
\end{tabular}

Note: Number of Level 1 units: $N=1518$; number of Level 2 units: $N=122$.

\section{References}

Babab, E. (2007). Teachers' nonverbal behaviors and its effects on students. In R. Perry \& J. C. Smart (Eds.), The scholarship of teaching and learning in highe education: An evidence-based perspective (pp. 201-261). New York: Springer.

Baumann, T., Schneider, C., Vollmar, M., \& Wolters, M. (2012). Schulen auf einen Blick. Wiesbaden: Statistisches Bundesamt.

Bergin, D. A. (1999). Influences on classroom interest. Educational Psychologist, 34, $87-98$

Black, A. E., \& Deci, E. L. (2000). The effects of instructors' autonomy support and students' autonomous motivation on learning organic chemistry: A selfdetermination theory perspective. Science Education, 84, 740-756.

Brophy, J. E., \& Good, T. L. (1986). Teacher behavior and student achievement. In M. Wittrock (Ed.). Handbook of research on teaching (Vol. 3, pp. 328-375). New York: Macmillan.
Burger, J. M., \& Arkin, R. M. (1980). Prediction, control, and learned helplessness. Journal of Personality and Social Psychology, 38, 482-491.

Butler, R. (1989). Interest in the task and interest in peers' work in competitive and noncompetitive conditions: A developmental study. Child Development, 60(3), 562-570.

Collins, M. L. (1978). Effects of enthusiasm training on preservice elementary teachers. Research in Teacher Education, 29, 53-57.

Csikszentmihalyi, M. \& Larson, R. (1987). Validity and reliability of the experiencesampling method. Journal of Nervous and Mental Disease, 175(9), 526-536. http://dx.doi.org/10.1097/00005053-198709000-00004.

Emmer, E. T., \& Stough, L. M. (2001). Classroom management: A critical part of educational psychology, with implications for teacher education. Educational Psychologist, 36(2), 103-112.

Feldman, K. A. (2007). Identifying exemplary teachers and teaching: Evidence from student ratings. In R. P. Perry \& J. C. Smart (Eds.), The scholarship of teaching and 
learning in higher education - An evidence-based perspective (pp. 93-143). Dordrecht: Springer.

Fraser, B. J., \& Walberg, H. J. (1981). Psychosocial learning environment in science classrooms: A review of research. Studies in Science Education, 8(1), 67-92. http://dx.doi.org/10.1080/03057268108559887.

Frenzel, A. C., Goetz, T., Lüdtke, O., Pekrun, R., \& Sutton, R. E. (2009). Emotional transmission in the classroom: Exploring the relationship between teacher and student enjoyment. Journal of Educational Psychology, 101(3), 705-716.

Frenzel, A. C., Pekrun, R., \& Goetz, T. (2007a). Girls and mathematics - A "hopeless" issue? A control-value approach to gender differences in emotions towards mathematics. European Journal of Psychology of Education, 22(4), 497-514.

Frenzel, A. C., Pekrun, R., \& Goetz, T. (2007b). Perceived learning environment and students' emotional experiences: A multilevel analysis of mathematics classrooms. Learning and Instruction, 17, 478-493.

Gage, N. L., \& Berliner, D. C. (1998). Educational psychology (6th ed.). New York: Houghton Mifflin.

Goetz, T. (2004). Emotionen und selbstreguliertes Lernen bei Schülern im Fach Mathematik [Students' emotions and self-regulated learning in mathematics]. Muenchen: Utz.

Goetz, T., Bieg, M., Lüdtke, O., Pekrun, R., \& Hall, N. C. (in press). Do girls really experience more anxiety in mathematics? Psychological Science (in press).

Goetz, T., Cronjaeger, H., Frenzel, A. C., Lüdtke, O., \& Hall, N. C. (2010). Academic selfconcept and emotion relations: Domain specificity and age effects. Contemporary Educational Psychology, 35, 44-58.

Goetz, T., Frenzel, C. A., Hall, N. C., \& Pekrun, R. (2008). Antecedents of academic emotions: Testing the internal/external frame of reference model for academic enjoyment. Contemporary Educational Psychology, 33, 9-33.

Goetz, T., Frenzel, A. C., Lüdtke, O., \& Hall, N. C. (2011). Between-domain relations of academic emotions: Does having the same instructor make a difference? The Journal of Experimental Education, 79, 84-101.

Goetz, T., Frenzel, A. C., Pekrun, R., \& Hall, N. C. (2006). The domain specificity of academic emotional experiences. The Journal of Experimental Education, 75(1), $5-29$.

Goetz, T., Frenzel, C. A., Pekrun, R., Hall, N. C., \& Lüdtke, O. (2007). Between- and within-domain relations of students' academic emotions. Journal of Educational Psychology, 99(4), 715-733.

Goetz, T., Frenzel, A. C., Stoeger, H., \& Hall, N. C. (2010). Antecedents of everyday positive emotions: An experience sampling analysis. Motivation and Emotion, 34, 49-62.

Goetz, T., Pekrun, R., Hall, N. C., \& Haag, L. (2006). Academic emotions from a socialcognitive perspective: Antecedents and domain specificity of students' affect in the context of Latin instruction. British Journal of Educational Psychology, 76(2), 289-308.

Goetz, T., Zirngibl, A., Pekrun, R., \& Hall, N. C. (2003). Emotions, learning and achievement from an educational-psychological perspective. In P. Mayring \& C. von Rhoeneck (Eds.), Learning emotions: The influence of affective factors on classroom learning (pp. 9-28). Frankfurt am Main: Peter Lang.

Haag, L., \& Goetz, T. (2012). Mathe ist schwierig und Deutsch aktuell. Vergleichende Studie zur Charakterisierung von Schulfächern aus Schülersicht [Math is difficult and German up to date: A study on the characterization of subject domains from students، perspective]. Psychologie in Erziehung und Unterricht, 59, 32-46.

Hatfield, E., Cacioppo, J. T., \& Rapson, R. L. (1994). Emotional contagion. New York, NY: Cambridge University Press.

Hektner, J. M., Schmidt, J. A., \& Csikszentmihalyi, M. (2007). Experience sampling method: Measuring the quality of everyday life. Thousand Oaks, CA: Sage Publications, Inc. (Retrieved from EBSCOhost).

Hox, J. J. (2010). Multilevel analysis: Techniques and applications (2nd ed.). New York and Hove: Routledge.

Hu, L., \& Bentler, P. M. (1999). Cutoff criteria for fit indexes in covariance structure analysis: Conventional criteria versus new alternatives. Structural Equation Modeling: A Multidisciplinary Journal, 6(1), 1-55. http://dx.doi.org/10.1080/ 10705519909540118.

Hugener, I., Pauli, C., Reusser, K., Lipowsky, F., Rakoczy, K., \& Klieme, E. (2009). Teaching patterns and learning quality in Swiss and German mathematics lessons. Learning and Instruction, 19(1), 66-78. http://dx.doi.org/10.1016/ j.learninstruc.2008.02.001.

Jang, H., Reeve, J., \& Deci, E. L. (2010). Engaging students in learning activities: It is not autonomy support or structure but autonomy support and structure. Journal of Educational Psychology, 102(3), 588-600. http://dx.doi.org/10.1037/ a0019682.

Kunter, M., \& Baumert, J. (2006). Who is the expert? Construct and criteria validity of student and teacher ratings of instruction. Learning Environments Research, 9, 231-251.

Lamiell, J. T. (1998). 'Nomothetic' and 'idiographic': Contrasting Windelband's understanding with contemporary usage. Theory \&' Psychology, 8(1), 23-38.

Marsh, H. W. (1982). SEEQ: A reliable, valid, and useful instrument for collecting students' evaluations of university teaching. British Journal of Educational Psychology, 52, 177-195.

Marsh, H. W. (1987). Students evaluations of University teaching: Research findings, methodological issues, and directions for future research.
International Journal of Educational Research, 11(3), 253-388. http://dx.doi.org/ 10.1016/0883-0355(87)90001-2.

Marsh, H. W., \& Ayotte, V. (2003). Do multiple dimensions of self-concept become more differentiated with age? The differential distinctiveness hypothesis. Journal of Educational Psychology, 94(4), 687-706.

Marsh, H. W., \& Bailey, M. (1993). multidimensional students' evaluations of teaching effectiveness: A profile analysis. The Journal of Higher Education, 64(1), $1-18$.

Marsh, H. W. (2007). Students' evaluations of university teaching: Dimensionality, reliability, validity, potential biases and usefulness. In R. P. Perry \& J. C. Smart (Eds.), The scholarship of teaching and learning in higher education (pp. 319-383). Dordrecht: Springer.

Meyer, D. K., \& Turner, J. C. (2006). Re-conceptualizing emotion and motivation to learn in classroom contexts. Educational Psychology Review, 18(4), 377-390.

Mottet, T. P., \& Beebe, S. A. (2002). Relationships between teacher nonverbal immediacy, student emotional response, and perceived student learning. Communication Research Reports, 19(1), 77-88. http://dx.doi.org/10.1080/ 08824090209384834

Mouratidis, A. A., Vansteenkiste, M., Sideridis, G., \& Lens, W. (2011). Vitality and interest-enjoyment as a function of class-to-class variation in need-supportive teaching and pupils' autonomous motivation. Journal of Educational Psychology, 103(2), 353-366.

Murray, H. G. (1983). Low-inference classroom teaching behaviors and student ratings of college teaching effectiveness. Journal of Educational Psychology, 75(1), 138-149. http://dx.doi.org/10.1037/0022-0663.75.1.138.

Muthén, L. K., \& Muthén, B. O. (2008). Mplus user's guide (5th ed.). Los Angeles, CA: Muthén \& Muthén.

Nett, U. E., Goetz, T., \& Hall, N. C. (2011). Coping with boredom in school: An experience sampling perspective. Contemporary Educational Psychology, 36(1), $49-59$.

Nylund, K., Nishina, A., Bellmore, A., \& Graham, S. (2007). Subtypes, severity, and structural stability of peer victimization: What does latent class analysis say? Child Development, 78(6), 1706-1722.

Patrick, B. C., Hisley, J., \& Kempler, T. (2000). "What's everybody so excited about?". The effects of teacher enthusiasm on student intrinsic motivation and vitality. Journal of Experimental Education, 68, 1521-1558.

Pekrun, R. (2006). The control-value theory of achievement emotions: Assumptions, corollaries, and implications for educational research and practice. Educational Psychology Review, 18, 315-341.

Pekrun, R., vom Hofe, R., Blum, W., Frenzel, A. C., Goetz, T. \& Wartha, S. (2007). Development of mathematical competencies in adolescence: The PALMA longitudinal study. In M. Prenzel (Ed.), Studies on the educational quality of schools. The final report of the DFG Priority Programme (pp. 17-37). Münster: Waxmann.

Pekrun, R., Goetz, T., Titz, W., \& Perry, R. P. (2002). Academic emotions in students' self-regulated learning and achievement: A program of qualitative and quantitative research. Educational Psychologist, 37(2), 91-105.

Prenzel, M., Artelt, C., Baumert, J., Blum, W., Hammann, M., Klieme, E., et al. (Eds.) (2008). Münster: Waxmann-Verlag.

Raudenbush, S. W., \& Bryk, A. S. (2002). Hierarchical linear models. Applications and data analysis methods (2nd ed.). Thousand Oaks: Sage.

Raudenbush, S. W., Bryk, A., \& Congdon, R. (2009). HLM 6.08. Hierarchical linear and nonlinear modeling. Lincolnwood: Scientific Software International.

Reise, S. P. Ventura, J., Nuechterlein, K. H., \& Kim, K. H. (2005). An illustration of multilevel factor analysis. Journal of Personality Assessment, 84(2), 126-136.

Robinson, W. P. (1975). Boredom at school. British Journal of Educational Psychology, $45,141-152$.

Rosenshine, B. (1970). Enthusiastic teaching: A review. School Review, 78, 499-514.

Scherer, K. R. Schorr, A, \& Johnstone, T. (Eds.). (2001). Appraisal processes in emotion: Theory, methods, research. New York: Oxford University Press.

Schwarz, G. (1978). Estimating the dimension of a model. The Annals of Statistics, 6(2), 461-464.

Seidel, T. \& Shavelson, R. J. (2007). Teaching effectiveness research in the past decade: The role of theory and research design in disentangling meta-analysis results. Review of Educational Research, 77(4), 454-499. http://dx.doi.org/ 10.3102/0034654307310317.

Seligman, M. E. P. (1975). Helplessness. San Francisco: Freeman.

Smith, C. A., \& Lazarus, R. S. (1993). Appraisal components, core relational themes, and the emotions. Cognition and Emotion, 7, 233-269.

Tong, E. M. W., Bishop, G. D., Enkelmann, H. C., Why, Y. P., Diong, S. M., Khader, M., et al. (2007). Emotion and appraisal: A study using ecological momentary assessment. Cognition and Emotion, 21(7), 1361-1381. http://dx.doi.org/ $10.1080 / 02699930701202012$.

Valsiner, J. (1986). Between groups and individuals: Psychologists' and laypersons' interpretation of correlational findings. In J. Valsiner (Ed.), The individual subject and scientific psychology (pp. 113-151). New York, NY: Plenum.

Walberg, H. J. (1990). Productive teaching and instruction: Assessing the knowledge base. The Phi Delta Kappan, 71(6), 470-478.

Wanous, J. P., Reichers, A. E., \& Hudy, M. J. (1997). Overall job satisfaction: How good are single-item measures? Journal of Applied Psychology, 82(2), 247-252. http:// dx.doi.org/10.1037/0021-9010.82.2.247.

Watson, D., \& Tellegen, A. (1985). Toward a consensual structure of mood. Psychological-Bulletin, 98(2), 219-235. 
Weiss, H.M., Beal, D.J., Lucy, S.L., \& MacDermid, S.M. (2004).Constructing EMA studies with PMAT: The purdue momentaryassessment tool user's manual. Retrieved from http://www.mfri.purdue.edu/pmat.

Wigfield, A., Battle, A., Keller, L. A., \& Eccles, J. S. (2002). Sex-differences in motivation, self-concept, career aspiration, and career choice: Implications for cognitive development. In A. McGillicuddy-De Lisi, \& R. De Lisi (Eds.), Biology, society, and behavior: The development of sex differences in cognition (pp. 93-124). Westport, CT: Ablex.

Wild, T. C., Enzle, M. E., \& Hawkins, W. L. (1992). Effects of perceived extrinsic versus intrinsic teacher motivation on student reactions to skill acquisition. Personality and Social Psychology Bulletin, 18, 245-251.

Zeidner, M. (1998). Test anxiety: The state of the art. New York: Plenum Press. 